\title{
A Research on Vocational College Students' Interest in Learning English from Perspective of Task-Based Language Teaching
}

\author{
Bojun Zou ${ }^{1, a}$ and Jianzhong Zhou ${ }^{2, b^{*}}$ \\ ${ }^{1}$ Graduate School, Jilin Agricultural University, Changchun, China \\ ${ }^{2}$ The Faculty of Arts and Humanities, Jilin Agricultural University, Changchun, China

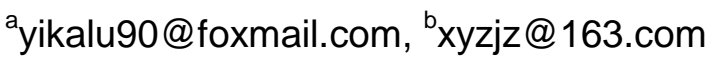

Keywords: Task-Based language teaching; Vocational education; Teaching reform

\begin{abstract}
This Task-Based Language Teaching (TBLT. abbreviation) is defined as a innovation teaching method which encourages learners to bring second language into full play and regards improvement of students' pragmatic competence as a goal. It is a common phenomenon that numerous vocational students take less interest in leaning English and play truant at times.

Based on summary of studies and related elementary theories, it is supposed to take the application of TBLT in vocational college English class as a starting point. Aimed to explore how to fire students' interest in learning English via TBLT and further arouse comprehensive English proficiency, qualitative and quantitative research will be adopted. It is believed that achievements in TBLT implemented in vocational English teaching will be enriched and the English teaching reform is destined to be deepened.
\end{abstract}

\section{Introduction}

It is higher vocational education that is employment-oriented and outputs high-quality skilled staff with construction and management ability as a target, of which essential characteristic determines to pay more attention to cultivating practical ability.

In the year of 2013, China State Department clearly stated in the "Decision on Accelerating the Development of Vocational Education" issued, to promote the innovation of training mode, spread cooperative learning and implement project teaching as well as process-oriented model. In order to satisfy the urgent demands of the world economic recovery, it requires that the majority of vocational colleges organically combine basic knowledge with communicative competence in training links.

By now, compared to the requests above, teaching effects in a number of vocational colleges may be reverse, yet. Because of last-standing discrimination, the students are always labeled with "good-for-nothing" "poor level". Therefore, both improvement of academic performance and harmonious personality are seriously restricted by the phenomenon of ignorance of English itself, lack of interest and shortage of motivation.

Nowadays, researches on TBLT mainly focus on the theoretical summary stage and less practical cases were accumulated. How to surmount the dilemma in practice? How to design tasks to stimulate students' learning interest? These problems listed above are urgently waited to be solved.

\section{Literature Review}

The soul of TBLT is "Do things in language". Application is considered as the purpose and provides students with an unprecedented practice space by participation, experience, interaction, exchange and cooperation to mobilize existing language resources.

The First and Primary Author. Bojun Zou, Postgraduate Student of Jilin Agricultural University, majors in Vocational and Technical Education, Bachelor of Arts of Dalian University of Foreigner Languages. 
Corresponding Author. Jianzhong Zhou, Dean of the Faculty of Arts and Humanities, Jilin Agricultural University, Professor, D.Eng, Supervisor of postgraduate students, Executive Director of China Agricultural Higher Education Research Association.

Abroad Summary of TBLT. TBLT theory came from Western Europe, initially experimented in the mid 20th century in India, shaped in seventies, in the late 1980s matured and widely used in Europe and North America.

A clear definition is the first prerequisite. Synthesizing the definitions resulted by Long, Prabhu, Nunan, Ellis and other scholars, it is believed that the task ought to be following qualities: the practice with a distinct purpose; continuous interpersonal activity; conscious thinking activity by wielding the target language. According to actual and professional requirements, the task, in this research, is ruled to be an activity by which students apply English to analyze and solve problems in simulation.

As for the degree of difficulty, Skenhan proposed " $3 \mathrm{C}$ Mode" complexity, cognitive complexity and communicative complexity. That is to say, when design a task, it is supposed to consult professional needs, consider students' interest and remember to regard students themselves as the center. Implementation is the keynote. Willis put forward three steps namely Pre-Task, Task-cycle and Language Focus.

In fact, TBLT and traditional "3P Mode" (Presentation, Practice, Production) ought to be adopted in accordance with the actuality rather than mutually replaced. It goes without saying that mutual supplement is certain to promote reform.

Hence, as it is observed, no matter in terms of definition, design and implementation, the abroad has formed a mature system. They are expounded detail and have been applied to the second language teaching. In recent years, research on TBLT has begun to get involved in social and cultural fields that suggests to open up a boundless vitality of the territory.

Domestic Current Status of TBLT. At the end of 1990s, the concept of TBLT was introduced by Jimei Xia etc., which began to spread across China. In the Early of 2000s, "English Curriculum Standards", was addressed by Ministry of Education and comprehensive practical ability was referred, which seemed a heated wave. "Focus-type Task-based Teaching" was proposed by Weili Fang. The initial spread of cognitive errors and progressive achievements were separately summarized by Guiqin Yang and Ling Tian.

Soon afterwards, TBLT gradually was employed to English teaching. By means of a flexible set tasks, the English grades of some high school experimental students were obviously enhanced by Junyi Liu. Yuelan Zhu took TBLT into college comprehensive English course, and pointed the necessity to cultivate pragmatic competence. Xiao Wang's experiment showed that the interest, in learning English of which the sample in a certain higher vocational school, was effectively stimulated and the grades were substantially increased. Shufeng Liu thoroughly analyzed its necessity and took a unit as a sample to illustrate the possibility .

Comments on Literature Review. Researches in domestic mostly focused on TBLT application in colleges and high schools, in favor of literature translation and theory induction, on the contrary, empirical cases in close connection with current situations of English teaching in vocational colleges are handful. Moreover, papers published in the same period revolved around the similar issue, demonstrated a high repetition rate.

Throughout the perspectives above, it could be easily found that they were either a single study of TBLT from a respect utilized into English class application or an exploration of the factors that affect the interest from psychology. It is pity that two perspectives originally united were separated and theoretical results deepened from practice were useless.

\section{Theoretical Foundations \& Soft Conditions}

Theoretical Foundations. Second Language Acquisition Theory. Krashen believes that the structure of language acquisition obeys along with a predictable order. Men naturally acquire language in communication by means of importing reading and listening materials which are a bit more 
complicated than current level and meanwhile noting the denotation of language itself. Emotional factors such as motivation, interests and personality which play an active role, are attached importance to by Krashen.

TBLT stresses the function of understanding which brings the second language acquisition theory into creative play and both interest in learning and comprehensive ability are premeditated at first place.

Constructive Learning Theory. Synthesizing the philosophies including Piaget's cognitive development comprehensive, Ausubel's meaningful learning theory, Bruner's discovery learning and social constructive learning theory, the cognitive structures discovered and perceived by learners are contents which are meaningful to them. Furthermore, subjective factors regarding background knowledge and attitudes, which is part of learners themselves, cannot bypassed at any time.

TBLT emphasizes the primary effect of implication, wherefore, it requires that the purpose of communicative tasks ought to be defined in order to ensure activities themselves to make a difference.

Multiple Intelligence Theory. In the framework of Canard's Multiple Intelligence, everyone's intelligence has different manifestations. That is to say, as long as there is adequate external influences and their own efforts, each individual will be able to develop and strengthen their own any kind of intelligence.

On the task-based classroom, teachers fully master students' intelligence features when designing tasks, and afterwards these which satisfy the zone of the proximal of the majority are devised. Students mobilize their comparative strengths as soon as prepare and cooperate to complete the task. Teachers are expected to tap subtle potential of students as multi-angle as possible, extend seasonable recognition and have students gain a sense of harvest.

Soft Conditions. High Probability of Experimenting. Two parallel classes specializing in Hotel Service at a higher vocational school in Dalian will be selected. Its possibility belongs to the fact the majority of the students chosen are enthusiastic, active and longing for more new knowledge related to their future job. Students newly enrolled suddenly stay away from the extremely tremendous pressure on the college entrance examination, tired with the traditional teaching model namely listento- write and test-to-test. On the contrary, fascinating, friendly and visual-image teaching style caters to them, which arouses desire for knowledge and makes a sense of achievement. According to observation, it is a piece of cake to find living themes in close connection with the task topics, in case that teachers timely guide and active classroom activities. Thus, it is uncomplicated to motivate enthusiasm, which contributes to carry out this teaching experiment.

Advantages of Professional Atmosphere. The first author is engaged in vocational and technical education whose direction is education management, which agrees to the professional requirements. Required courses have been mastered and the skill of theory into practice has been formed after two academic semesters.

Jilin Agricultural University, where the author is studying, is equipped with excellent conditions from material assets, professional teachers to academic atmosphere. She was one of the most earliest established Master Degree Programs of Vocational and Technical Education; "National Key Construction of Vocational Teachers' Training Base" titled by the Ministry of Education.

\section{Research Objects \& Methods}

\section{Research Objects.}

1) The sample's interest in learning English will be excited, held and extended for longer time through implementation

2) Students' comprehensive competence (English) will be obviously upgraded.

3) It might as well try to promote the application of TBLT in higher vocational English class in Dalian City, China.

Research Methods. Literature Review. Use various channels to collect and organize documents and materials so as to obtain a theoretical knowledge about the method of this study as the main 
purpose. Depending on these data identification, classification, master academic achievements at home and abroad in this research.

Classroom Observation. In order to observe and record actual situations, it is going to step into the front line of English classroom. Numerous real, typical, general psychology and behavior of interviewees is investigated in purpose.

Comparative Experiment. Two parallel classes selected is going to be respectively made full use of traditional teaching method and TBLT. After a semester, compare whether context interest is different and furthermore analyze impacts brought by TBLT on students interested in learning English.

\section{Summary}

Specifically, it is paid attention to vocational college students who are always neglected by society and put TBLT application in vocational required English as an intervention. It is considered timely to fill up the gaps of the existing research and broaden the perspective of teaching reform in vocational theoretical research.

It is encouraged that previous similar studies vague style is abandoned. Combined with related empirical cases, it strives to provide targeted recommendations on how to enhance English proficiency of vocational college students. It is a fruitful practice to cultivate high-quality technical talents, which demonstrates to be a potential value and it hopes to offer an available reference for further similar studies.

\section{Acknowledgment}

I would like to express my gratitude to all those who helped me during the writing of this thesis.

My deepest gratitude goes first and foremost to Professor Jianzhong Zhou, my supervisor, who has walked me through all the stages of the writing. His unwavering support has sustained me through frustration and depression.

I am also deeply indebted to all the other teachers and schoolmates in Jilin Agricultural University for their direct and indirect help to me.

Last but not the least, my gratitude also extends to my family who have been assisting, supporting and caring for me all of my life.

\section{References}

[1] Robert J. Sternberg. Cognitive Psychology (Third Edition)[M] Beijing: Language Teaching and Research Press, 2003.

[2] Herbert J.Rubin. Qualitative Interviewing: The Art Of Hearing Data[M] Chongqing: Chongqing University Press, 2010.

[3] Peter W. Airasian. Classroom Assessment: Concepts \& Applications (Fourth Edition)[M] Shanghai:East China Normal University Press, 2008.

[4] Richards, Rodgers. Approaches and Methods in Language Teaching [M]. Cambridge: Cambridge University Press, 2000.

[5] Nunan, David. Second Language Teaching and Learning [M]. Beijing: Language Teaching and Research Press, 2001.

[6] Ellis, R. Task-Based Learning and Teaching [M]. Oxford: Oxford University Press, 2003.

[7] Bygate, M. Researching Pedagogic Tasks: Second Language Learning, Teaching and Testing[M]. London: Longman, 2011.

[8] Johnson K. An Introduction to Foreign Language Learning and Teaching [M]. Beijing: Language Teaching and Research Press, 2003. 
[9] Nunan, David. Second Language Teaching and Learning [M]. Beijing:Language Teaching and Research Press, 2001 